\title{
The impact of a successful treatment of HCV on glyco-metabolic control in diabetic patients
}

Carla Carnovale, Marta Gentili, Carlo Magni, Faizan Mazhar, Giulia Mosini, Emilio Clementi, Sonia Radice

Antiviral Therapy 2019; 10.3851/IMP3300

Submission date Acceptance date Publication date 19th December 2018

21st January 2019

5th March 2019

This provisional PDF matches the article and figures as they appeared upon acceptance. Copyedited and fully formatted PDF and full text (HTML) versions will be made available soon.

For information about publishing your article in Antiviral Therapy go to http://www.intmedpress.com/index.cfm?pid=12 


\title{
Letter
}

\section{The impact of a successful treatment of HCV on glyco-metabolic control in diabetic patients}

\author{
Carla Carnovale ${ }^{1}$, Marta Gentili', Carlo Magni2, Faizan Mazhar ${ }^{1}$, Giulia Mosini', Emilio \\ Clementi $^{1,3 *}$, Sonia Radice ${ }^{1}$ \\ ${ }^{1}$ Unit of Clinical Pharmacology, Department of Biomedical and Clinical Sciences L. Sacco, "Luigi Sacco" \\ University Hospital, Università di Milano, Milan, Italy \\ ${ }_{21} 1^{\text {st }}$ Division of Infectious Diseases, ASST Fatebenefratelli-Sacco, Milan, Italy \\ ${ }^{3}$ Scientific Institute IRCCS Eugenio Medea, Lecco, Italy
}

${ }^{*}$ Corresponding author e-mail: emilio.clementi@unimi.it

Accepted 21 January 2019, published online 5 March 2019

Dear Editor,

We read with interest the review by Adinolfi et al highlighting the need to evaluate all persons with Hepatitis C Virus (HCV) infection for diabetes, in view of extrahepatic benefits of viral eradication, the reduced risk of diabetic complications and improved glyco-metabolic control in HCV-infected patients [1]. Previous studies have shown that HCV impairs glucose metabolism directly via viral proteins and indirectly by altering pro-inflammatory cytokine levels [2-4]; thus, in turn, HCV clearance may positively impact on glucose metabolism, as evidenced by decreased mean haemoglobin A1c (HbA1c) and fasting plasma glucose (FPG) levels [5,6] in diabetic patients exposed to new Direct Acting Antiviral (DAA) agents that produce a Sustained Virological Response (SVR) in nearly all cases. However, there are limited data on the effect of viral eradication with DAAs on established type 2 diabetes (T2DM) and whether the benefits are persistent $[7,8]$.

In view of the clinical importance of the above issue, we assessed if a correlation between HCV eradication following DAA-based therapy and improvement in glyco-metabolic control occurred in our study population and if it was maintained after the end of treatment (EOT). We retrospectively compared $\mathrm{HbA} 1 \mathrm{c}$ and FPG levels at baseline and post-SVR (at 12 weeks) in 93 patients with T2DM exposed to DAAs for HCV eradication (Figure 1 show the selection process of patients with HCV and diabetes enrolled in the study). To evaluate the glycometabolic response, we used a composite end-point given by the reduction of plasma glucose levels of at least $20 \mathrm{mg} / \mathrm{dl}(1.1 \mathrm{mmol} / \mathrm{L})$ and a reduction of $\mathrm{HbA} 1 \mathrm{c}$ of $0.5 \%$ compared to baseline values as a significant improvement in the glyco-metabolic response, as previously reported in some studies that addressed the issue $[9,10]$.

As reported in Table 1, we found a significant post-SVR level reduction both of plasma glucose $(\mathrm{P}=0.0378)$ and $\mathrm{HbA} 1 \mathrm{c}$ values $(\mathrm{P}=0.0039)$, as previously reported by four similar retrospective studies [5,911]. In contrast with our findings, no change in $\mathrm{HbA} 1 \mathrm{c}$ was found 12-weeks post SVR by Stine et al among $26 \mathrm{HCV}$ diabetic patients treated with SOF/LED $(P=0.268)$ [12] and also Carvalho et al failed to identify maintained post-SVR benefits in terms of plasma glucose level reduction in patients without diabetes exposed to DAAs [8]. Furthermore, two previous studies found no significant difference in changes in HbA1c and glucose levels from baseline to the last follow-up in subjects who achieved SVR in a mixed cohort of 
diabetic and non-diabetic patients [7,13]. These conflicting results may be in part attributable to the fact that our median HbA1c levels at baseline were higher $(59.19 \pm 16.31 \mathrm{mmol} / \mathrm{mol} ; 7.6 \%)$ than the ones reported in the studies mentioned before, suggesting that an improvement in glyco-metabolic response is more likely to occur in patients with established diabetes and with high baseline levels of HbA1c. In line with this hypothesis, as correctly reported by Adinolfi et al in their interesting review [1], Hum et al found drops in $\mathrm{HbA} 1 \mathrm{c}$ associated with SVR restricted to diabetic patients with a high baseline $\mathrm{HbA} 1 \mathrm{c}$ (mean $\mathrm{HbA} 1 \mathrm{c}>7.2 \%$ ), whereas among diabetic patients with pre-treatment $\mathrm{HbA} 1 \mathrm{c} \leq 7.2 \%$ there was no significant difference based on SVR [5].

A recent meta-analysis quantifying variations of glyco-metabolic indicators attributed to DAA therapy in diabetic patients detected a significant improvement in glyco-metabolic control after HCV eradication, in terms of HbA1c $(-0.45 \% ; \mathrm{P}<0.001)$ and mean plasma glucose $(-22.03 \mathrm{mg} / \mathrm{dL} ; \mathrm{P}=0.03)$ levels reduction, following DAA treatment in patients with established diabetes [14]. However, these promising findings came from a limited number of studies performed in a wide variety of clinical settings and need to be confirmed.

In conclusion, an increasing number of evidence seems to suggest that the eradication of HCV with DAA therapy may play a role in improving glycemic control in patients with established T2DM, highlighting the need to explore the issue through more wide-ranging studies, with a more complete baseline assessment and a prolonged follow-up, with a view to a possible tapering of anti-diabetic drugs in order to avoid hypoglycaemic events.

\section{Funding}

None

\section{Acknowledgments}

This study was supported by the Agenzia Italiana del Farmaco (AIFA, to EC), by the Centre of Pharmacovigilance of Regione Lombardia (MEAP project, Monitoraggio degli Eventi Avversi nelle Popolazioni a Rischio, to EC).

\section{Conflict of interest}

The authors declare that there is no conflict of interest regarding the publication of this article

\section{References}

1. Adinolfi LE, Jacobson I, Bondin M, Cacoub P. Expert opinion on managing chronic HCV infection in patients with type 2 diabetes mellitus. Antivir Ther 2018; 23:11-21.

2. Kawaguchi T, Yoshida T, Harada M, et al. Hepatitis $\mathrm{C}$ virus down-regulates insulin receptor substrates 1 and 2 through up-regulation of suppressor of cytokine signaling 3. Am J Pathol 2004; 165:1499-1508.

3. Parvaiz F, Manzoor S, Tariq H, Javed F, Fatima K, Qadri I. Hepatitis C virus infection: molecular pathways to insulin resistance. Virol J 2011; 18:474.

4. Lecube A, Hernández C, Genescà J, Simó R. Proinflammatory cytokines, insulin resistance, and insulin secretion in chronic hepatitis C patients: a case-control study. Diabetes Care 2006; 29:1096-1101.

5. Hum J, Jou JH, Green PK, Berry K, Lundblad J, Hettinger BD. Improvement in Glycemic Control of Type 2 Diabetes After Successful Treatment of Hepatitis C Virus. Diabetes Care 2017; 40:1173-1180.

6. Ciancio A, Bosio R, Bo S, et al. Significant improvement of glycemic control in diabetic patients with HCV infection responding to direct-acting antiviral agents. J Med Virol 2018; 90:320-327. 
7. Chaudhury CS, Sheehan J, Chairez C, et al. No Improvement in Hemoglobin A1c Following Hepatitis C Viral Clearance in Patients With and Without HIV. J Infect Dis 2017; 217:47-50.

8. Carvalho JR, Velosa J, Serejo F. Lipids, glucose and iron metabolic alterations in chronic hepatitis C after viral eradication-comparison of the new direct-acting antiviral agents with the old regimens. Scand $J$ Gastroenterol 2018; 20:1-7.

9. Beig J, Orr D, Harrison B, Gane E. HCV Eradication with New IFN Free Treatment Improves Metabolic Profile In HCV-related Liver Transplant Recipients. Liver Transp/ 2018; 24:1031-1039.

10. Abdel Alem S, Elsharkawy A, Fouad R, et al. Improvement of glycemic state among responders to Sofosbuvir-based treatment regimens: Single center experience. J Med Virol 2017; 89:2181-2187.

11. Fabrizio C, Procopio A, Scudeller L, et al. HCV and diabetes: towards a 'sustained' glycaemic improvement after treatment with DAAs? Clin Microbiol Infect 2017; 23:342-343.

12. Stine JG, Wynter JA, Niccum B, et al. Effect of treatment with direct acting antiviral on glycemic control in patients with diabetes mellitus and chronic hepatitis C. Ann Hepatol 2017; 16:215-220.

13. Huang JF, Huang CF, Yeh ML, et al. The outcomes of glucose abnormalities in chronic hepatitis C patients receiving interferon-free direct antiviral agents. J Med Sci 2017; 33:567-571.

14. Carnovale C, Pozzi M, Dassano A, et al. The impact of a successful treatment of hepatitis $C$ virus on glyco-metabolic control in diabetic patients: a systematic review and meta-analysis. Acta Diabetol 2018; [Epub ahead of print].

Table 1. Baseline demographics and effect of treatment of HCV with DAAs on glyco-metabolic parameters Baseline demographics for HCV patients with diabetes with pre-and post-treatment laboratory values

\begin{tabular}{|c|c|c|c|}
\hline $\begin{array}{l}\text { Age (years), } \\
\text { mean } \pm S D\end{array}$ & $64 \pm 11$ & - & - \\
\hline Male, gender, n (\%) & $72(73 \%)$ & - & - \\
\hline \multicolumn{4}{|l|}{ Genotype, n (\%) } \\
\hline 1 & 47 (55,9\%) & & \\
\hline 2 & $18(21,4 \%)$ & - & - \\
\hline 3 & $13(15,4 \%)$ & - & - \\
\hline 4 & $8(9,5 \%)$ & - & - \\
\hline not performed & $9(10,7 \%)$ & - & - \\
\hline \multicolumn{4}{|c|}{ Changes in laboratory values } \\
\hline & Before [mean \pm SD] & After [mean \pm SD] & $P$ value ${ }^{*}$ \\
\hline $\begin{array}{l}\text { Mean plasma } \\
\text { glucose levels, } \\
\mathrm{mg} / \mathrm{dL}\end{array}$ & $166.9 \pm 50.63$ & $149.9 \pm 49.53$ & 0.0378 \\
\hline $\begin{array}{l}\text { Hemoglobin A1c, } \\
\mathrm{mmol} / \mathrm{mol}\end{array}$ & $59.19 \pm 16.31$ & $49.81 \pm 16.25$ & 0.0039 \\
\hline Total cholesterol, & $164.2 \pm 35.13$ & $182.4 \pm 38.54$ & 0.0010 \\
\hline Triglycerides, mg/dL & $186.3 \pm 83.27$ & $173.9 \pm 101.6$ & 0.5268 \\
\hline
\end{tabular}

SD: standard deviation; HCV: Hepatitis C Virus ; DDA: Direct Acting Antiviral.

* Statistical significance assessed by paired Student's t-test. $P$ values $<0.05$ were considered statistically significant. 
Figure 1. Selection process of patients with $\mathrm{HCV}$ and diabetes enrolled in the study

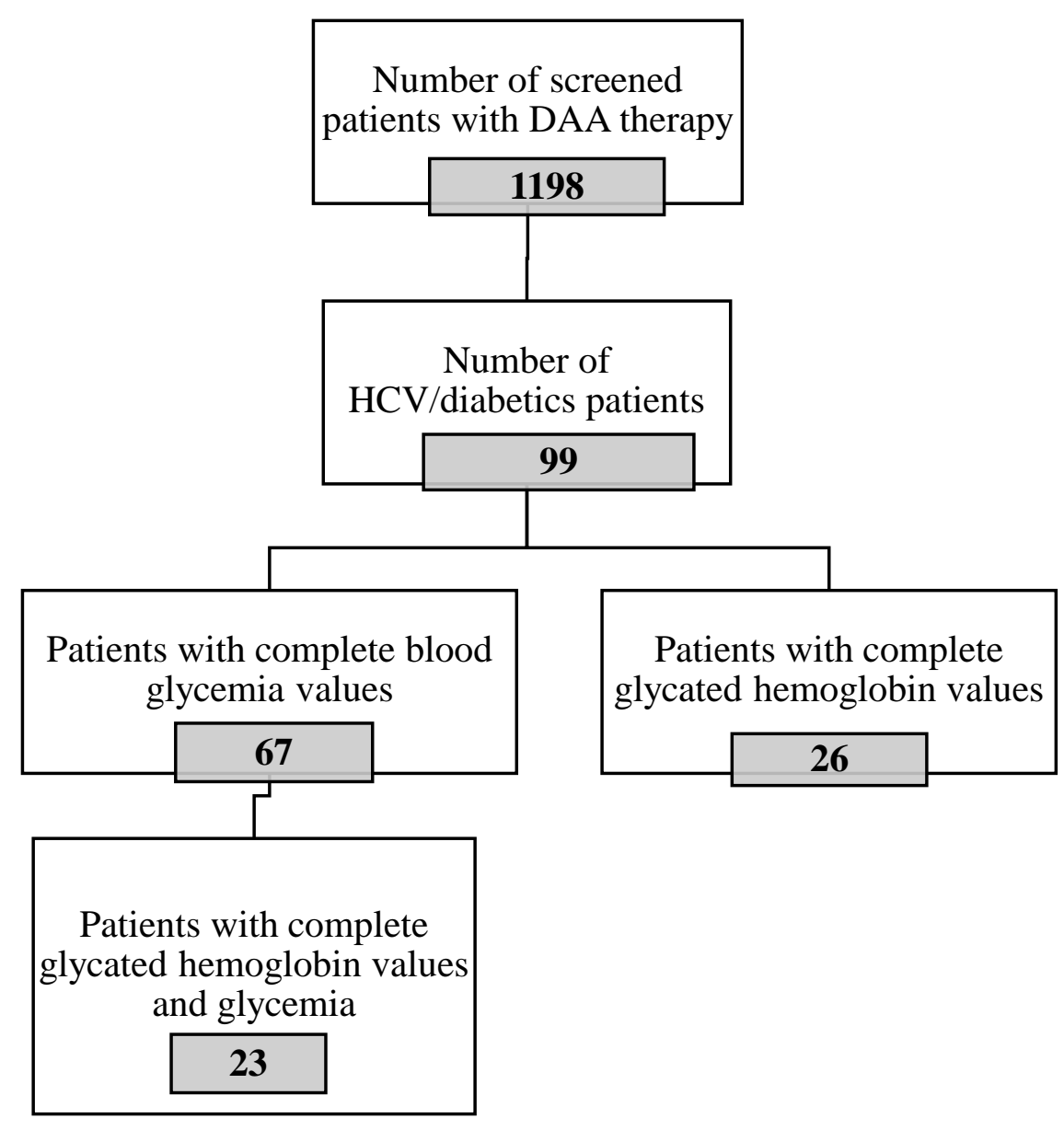

